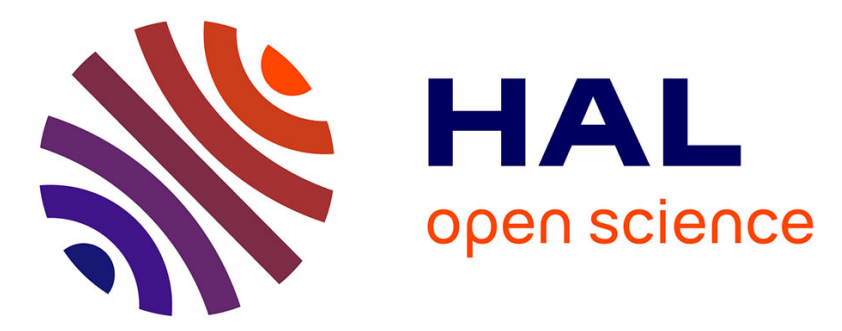

\title{
Imaging the neuroimmune response to alcohol exposure in adolescent baboons: a TSPO PET study using $\left[{ }^{18}\right.$ F $]$ DPA-714
}

Wadad Saba, Sébastien Goutal, Sylvain Auvity, Bertrand Kuhnast, Christine Coulon, Virginie Kouyoumdjian, Irène Buvat, Claire Leroy, Nicolas Tournier

\section{To cite this version:}

Wadad Saba, Sébastien Goutal, Sylvain Auvity, Bertrand Kuhnast, Christine Coulon, et al.. Imaging the neuroimmune response to alcohol exposure in adolescent baboons: a TSPO PET study using $\left[{ }^{18}\right.$ F $]$ DPA-714. Addiction Biology, 2018, 23 (5), pp.1000-1009. 10.1111/adb.12548 . cea-02937772

\section{HAL Id: cea-02937772 https://hal-cea.archives-ouvertes.fr/cea-02937772}

Submitted on 14 Sep 2020

HAL is a multi-disciplinary open access archive for the deposit and dissemination of scientific research documents, whether they are published or not. The documents may come from teaching and research institutions in France or abroad, or from public or private research centers.
L'archive ouverte pluridisciplinaire HAL, est destinée au dépôt et à la diffusion de documents scientifiques de niveau recherche, publiés ou non, émanant des établissements d'enseignement et de recherche français ou étrangers, des laboratoires publics ou privés. 
Imaging the neuroimmune response to alcohol exposure in adolescent baboons: a TSPO PET study using ${ }^{18}$ F-DPA-714

Wadad Saba ${ }^{1}$, Sébastien Goutal ${ }^{1}$, Sylvain Auvity ${ }^{1}$, Bertrand Kuhnast ${ }^{1}$, Christine Coulon ${ }^{1}$, Virginie Kouyoumdjian ${ }^{1}$, Irène Buvat ${ }^{1}$, Claire Leroy ${ }^{1}$, Nicolas Tournier $^{1}$

1. Imagerie Moléculaire In Vivo, IMIV, CEA, Inserm, CNRS, Univ. Paris-Sud, Université Paris Saclay, CEA-SHFJ, Orsay, France

First author, corresponding author: Wadad Saba

Address: IMIV, CEA-SHFJ, 4, place du Général Leclerc 91400 Orsay, France.

Phone: +33 (0)1 698677 52; Fax: +33 (0)1 698677 86;

E-mail: wadad.saba@cea.fr

Short running foot line: Imaging alcohol neuroimmunity

Diclosure: None

\section{Word count:}

Whole manuscript: 4,075

Abstract: 224

23 pages, 5 figures, 1 Table

References: 42 


\section{ABSTRACT}

The effects of acute alcohol exposure to the central nervous system are hypothesized to involve the innate immune system. The neuroimmune response to an initial and acute alcohol exposure was investigated using Translocator Protein 18 kDa (TSPO) PET imaging, a non-invasive marker of glial activation, in adolescent baboons. Three different alcoholnaive adolescent baboons (3-4 years old, 9 to $14 \mathrm{~kg}$ ) underwent ${ }^{18} \mathrm{~F}$-DPA-714 PET experiments before, during and 7-12 months after this initial alcohol exposure (0.7-1.0 g/L). The brain distribution of ${ }^{18} \mathrm{~F}-\mathrm{DPA}-714\left(\mathrm{~V}_{\mathrm{T}}\right.$; in $\left.\mathrm{mL} . \mathrm{cm}^{-3}\right)$ was estimated in several brain regions using the Logan Plot analysis and the metabolite-corrected arterial input function. Compared to alcohol-naive animals $\left(\mathrm{V}_{\mathrm{T} \text { brain }}=3.7 \pm 0.7 \mathrm{~mL} . \mathrm{cm}^{-3}\right)$, the regional $\mathrm{V}_{\mathrm{T}} \mathrm{s}$ of ${ }^{18} \mathrm{~F}$-DPA-714 were significantly increased during alcohol exposure $\left(V_{T}\right.$ brain $\left.=7.2 \pm 0.4 \mathrm{~mL} . \mathrm{cm}^{-3} ; \mathrm{p}<0.001\right)$. Regional $\mathrm{V}_{\mathrm{T}} \mathrm{S}$ estimated several months after alcohol exposure $\left(\mathrm{V}_{\mathrm{T}}\right.$ brain $\left.=5.7 \pm 1.4 \mathrm{~mL} . \mathrm{cm}^{-3}\right)$ were lower $(p<0.001)$ than those measured during alcohol exposure, but remained significantly higher $(p<0.001)$ than in alcohol-naive animals. The acute and long-term effects of ethanol exposure were observed globally across all brain regions. Acute alcohol exposure increased the binding of ${ }^{18} \mathrm{~F}-\mathrm{DPA}-714$ to the brain in a nonhuman primate model of alcohol exposure that reflects the "binge drinking" situation in adolescent individuals. The effect persisted for several months, suggesting a "priming" of glial cell function after initial alcohol exposure.

Keywords: Binge Drinking, Ethanol, Neuroinflammation, Neuroimmunity, Non-human primate, Positron Emission Tomography. 


\section{INTRODUCTION}

A wealth of research has addressed the effects of both acute and chronic alcohol consumption on the central nervous system (CNS) (Lovinger \& Crabbe 2005). In this representative field of translational research, imaging techniques have been useful to noninvasively study the impact of ethanol exposure to the brain (Bühler \& Mann 2011). The immediate effects of acute alcohol are mainly attributed to its rapid and direct action on ion channels, especially the gamma-aminobutyric acid alpha $\left(\mathrm{GABA}_{\mathrm{A}}\right)$ system (Trudell et al. 2014). The long-term alcohol-induced brain disorders have been mainly related to alterations of neurotransmission as well as neuronal function and plasticity (Bühler \& Mann 2011). Most clinical studies have focused on chronic alcoholism rather than intermittent ethanol exposure that reflects the "binge drinking" practice. Binge drinking is commonly defined as drinking 4-5 drinks in a single session or drinking resulting in a blood alcohol concentration $>0.8 \mathrm{~g} / \mathrm{L}$ (Fillmore \& Jude 2011). This practice is popular and highly prevalent in teenagers but its impact on the CNS is not fully understood yet (Pedersen \& von Soest 2015). Many studies suggest that adolescent binge drinking leads to long-lasting changes in the adult brain which may increase the prevalence of psychopathology in adults, including alcohol dependence (Crews et al. 2016; Morris et al. 2017).

It is now widely known that interaction of ethanol itself and/or its metabolites with the immune system may also play a pivotal role on the effects of alcohol on the CNS (Alfonso-Loeches et al. 2010). In the brain, the hallmark of neuroimmune responsiveness is the activation of glial cells (Jacobs et al. 2012). It was reported that chronic alcohol exposure promotes glial activation via microglia and astrocytes that release free radicals (Haorah et al. 2008), cytokines and inflammatory mediators (Vetreno \& Crews 2014; Pascual et al. 2016). It is also admitted that neuroimmune signaling is a key component of alcohol abuse (Mayfield et al. 2013) and neurotoxicity (Haorah et al. 2008), especially in the developing brain (Saito et al. 2016). Preclinical experiments, mainly performed in rodents, have clearly shown that alcoholinduced alterations in glial cell functions dramatically affect neuronal development, survival 
and function and ultimately impair the development of the proper brain architecture and connectivity (Guizzetti et al. 2014). Moreover, several behavioral and genetic studies suggest a role for innate immunity in alcohol abuse, addictive behavior and neurotoxicity in both animals and humans (Mayfield et al. 2013). Interestingly, it was shown that attenuation of microglial and interleukin-1 (IL-1) signaling protects mice from alcohol-induced sedation and/or motor impairment (Wu et al. 2011). Moreover, modulation of glial function using ibudilast was shown to reduce alcohol consumption in rodent models of alcohol exposure and dependence (Bell et al. 2015). This suggests that neuroimmunity may play a role in alcohol drinking behavior and reward (Blednov et al. 2012; Montesinos et al. 2016).

Positron emission tomography (PET) imaging using radiolabeled ligands of the translocator protein-18 kDa (TSPO) is the most advanced approach allowing for the non-invasive investigation of glial activation. Baseline TSPO expression in the brain under physiological conditions is low and contrasts with measurable TSPO overexpression detected during glial activation related to neuroinflammatory diseases (Vivash \& O'Brien 2016). Several TSPO radioligands, including ${ }^{18} \mathrm{~F}$-DPA-714, have reached the clinical status and are currently used to investigate the neuroimmune component of various patho-physiological states of the CNS in human (Lavisse et al. 2015; Hamelin et al. 2016). Moreover, this methodology allows for longitudinal studies in highly relevant species, including nonhuman primates, to study the kinetics of glial activation during neuroinflammatory states (Lavisse et al. 2014) or the neuroimmune response to drug exposure (Saba et al. 2015; Auvity et al. 2016).

For the present study, a nonhuman primate model of controlled alcohol exposure that mimics the binge drinking situation was developed. ${ }^{18} \mathrm{~F}$-DPA-714 PET imaging was performed to investigate the immediate and long-term effects of initial ethanol exposure on glial cell activity in alcohol-naive adolescent baboons. 


\section{MATERIAL AND METHODS}

\section{Animals and ethical approval}

A total of 6 adolescent (3-4 years-old; $9-15 \mathrm{~kg}$ ) and 3 adult (9-10 years-old; $25-30 \mathrm{~kg}$ ) Papio Anubis male baboons, obtained from Celphedia (Rousset-sur-Arc, France), were used for this study. Animal use procedures were in strict accordance with the recommendations of the European Community (86/609/CEE) and the French National Committee (Décret 87/848) for the care and use of laboratory animals. All procedures performed in studies were in accordance with the ethical standards of the institution or practice at which the study were conducted. The experimental protocol was evaluated by a local ethic committee (CETA Reference $n^{\circ}$ 14_004). Two adolescent animals were used to set-up and evaluate the tolerance of the ethanol infusion protocol and prepare the ${ }^{18} \mathrm{~F}$-DPA-714 PET study (set-up group). Four dedicated and alcohol-naive adolescent animals were included in the longitudinal imaging study. The impact of alcohol exposure on ${ }^{18} \mathrm{~F}-\mathrm{DPA}-714$ binding to plasma proteins was assessed in 3 adult baboons.

\section{Drugs, chemicals and radiochemicals}

Solutions of unlabeled racemic PK-11195 (gift from Sanofi, France) were prepared by dissolving 2-3 mg of the compound in DMSO (0.2 $\mathrm{mL})$, followed by dilution with PEG 400 (1 $\mathrm{mL}$ ) and $\mathrm{NaCl} 0.9 \%(2 \mathrm{~mL})$. Ethanol for i.v injection was obtained from Cooper (Melun, France).

DPA-714 was labeled with fluorine-18 (half-life, $109.8 \mathrm{~min}$ ) at its 2-fluoroethylmoiety using a tosyloxy-for-fluorine nucleophilic aliphatic substitution, according to procedures already reported, and using a commercially available GE TRACERLab FX-FN synthesizer (GE Medicam Systems, Buc, France) (Kuhnast et al. 2012). Typically, $\sim 10 \mathrm{GBq}{ }^{18} \mathrm{~F}-\mathrm{DPA}-714$ were routinely obtained within 60 min, including HPLC purification and formulation. Ready-toinject, $>99 \%$ radiochemically pure ${ }^{18} \mathrm{~F}$-DPA-714 (formulated in physiological saline containing 
less than $10 \%$ of ethanol) was obtained with $15-20 \%$ non-decay-corrected yields and specific radioactivities at the end of the radiosynthesis ranging from 37 to $148 \mathrm{GBq} / \mu \mathrm{mol}$.

\section{Ethanol exposure protocol}

A model of controlled ethanol exposure was developed in 2 healthy male baboons (4 yearsold; 14-15 kg). Based on clinical protocols of ethanol infusion (Ekins et al. 1985), different ethanol doses and infusion rates were tested in order to maintain a controlled blood ethanol concentration ( $<1 \mathrm{~g} / \mathrm{L})$. Ethanol for i.v injection was diluted at $20 \%(v / v)$ in $\mathrm{NaCl} 0.9 \%$. Animals were injected a bolus $(0.6 \mathrm{~g} / \mathrm{kg}$ in $10 \mathrm{~min})$ followed by ethanol infusion $(0.1 \mathrm{~g} / \mathrm{kg} / \mathrm{h})$ using an electrical syringe pump.

During PET experiments, ethanol concentration in plasma was measured during ethanol infusion at 30, 60 90, 120 and 180 min. Ethanol determination was performed using gas chromatography as previously described (Kristoffersen et al. 2006). The system consisted in a head-space gas chromatograph (GC Clarus 580, Perkin Elmer, Villebon-sur-Yvette, France) equipped with a headspace sampler TurboMatrix $40\left(\mathrm{~T}^{\circ} \mathrm{C}\right.$ needle: $120{ }^{\circ} \mathrm{C} ; \mathrm{T}^{\circ} \mathrm{C}$ transfer: $180{ }^{\circ} \mathrm{C}$; $\mathrm{T}^{\circ} \mathrm{C}$ oven: $80^{\circ} \mathrm{C}$, Perkin Elmer) and a flame ionization detector $\left(250^{\circ} \mathrm{C}\right.$, air flow rate: $450 \mathrm{~mL} \cdot \mathrm{min}^{-1}$; hydrogen flow rate: $45 \mathrm{~mL} \cdot \mathrm{min}^{-1}$ ). The temperature of the capillary column CP-select 624 (30 m x $0.53 \mathrm{~mm}, 3 \mu \mathrm{m}$, Varian, Buc, France) was maintained at $40^{\circ} \mathrm{C}$ during $5 \mathrm{~min}$. Briefly, $100 \mu \mathrm{L}$ of plasma was added with $1 \mathrm{~mL}$ of aqueous isopropanol solution $\left(80 \mathrm{mg} \cdot \mathrm{L}^{-1}\right)$. The preparation was then immediately placed in the headspace sampler.

\section{Imaging study}

\section{Study design}

Four alcohol-naive baboons (3-4 year old, 9 to $14 \mathrm{~kg}$ ) were included in the longitudinal PET study. Three animals underwent 3 subsequent ${ }^{18} \mathrm{~F}$-DPA-714 PET experiments. The first experiment was performed prior to any exposure to alcohol (baseline). After 2 to 4 months, a second PET experiment was performed during ethanol exposure to address the acute effects 
of alcohol (acute): ${ }^{18} \mathrm{~F}-\mathrm{DPA}-714$ was injected $30 \mathrm{~min}$ after the start of alcohol infusion, at the plateau of ethanol blood concentrations. Several months (7-12 months) after this initial alcohol exposure, each animal underwent a third ${ }^{18}$ F-DPA-714 PET scan to assess its longterm impact (long-term). An additional alcohol-naïve animal was used to assess the impact of repeated imaging procedures, including repeated anesthesia, on ${ }^{18} \mathrm{~F}-\mathrm{DPA}-714$ binding to the brain. This "control" animal underwent a first ${ }^{18}$ F-DPA-714 PET scan followed by two subsequent scans performed 4 and 14 months after, respectively, in the absence of any alcohol exposure.

\section{Animal preparation}

PET experiments were performed as previously described (Saba et al. 2015). One hour before PET acquisition, animals received ketamine $(10 \mathrm{mg} / \mathrm{kg}$ i.m) to induce anesthesia and prepare the PET experiment. After being intubated, a catheter was inserted in a sural vein for tracer and unlabeled PK-11195 administration. Another sural vein catheter was dedicated to propofol infusion. A femoral artery catheter was inserted for blood sampling dedicated to input function and ethanol concentration measurement. A femoral vein was dedicated to ethanol infusion. After being positioned in the PET scanner, animals were maintained anesthetized with i.v bolus of propofol $(2 \mathrm{~mL})$ followed by a 16 to $22 \mathrm{~mL} \cdot \mathrm{h}^{-1}$ i.v infusion under oxygen ventilation. The tidal volume was adjusted to achieve stable end-tidal carbon dioxide tension between 38 and $42 \mathrm{mmHg}$. Heart rate and rectal temperature were monitored throughout the experiment.

\section{MR and ${ }^{18}$ F-DPA-714 PET imaging}

First, each animal underwent a 3D T1-weighted brain MR scan (Achieva 1.5 T, Philips, Amsterdam, The Netherlands). Then, ${ }^{18}$ F-DPA-714 brain kinetics were assessed using a $\mathrm{HR}+$ Exact positron tomograph (Siemens Healthcare, Knoxville, TN). The head of the baboon was positioned in the tomograph using a custom-designed stereotaxic head holder. Head transmission scans were acquired for 10 min using three retractable germanium-68 rod 
sources. Animals were i.v. injected with ${ }^{18} \mathrm{~F}-\mathrm{DPA}-714(188 \pm 61 \mathrm{MBq})$. Dynamic PET data were acquired over the brain in 3-dimensional mode with the animal supine. Measured attenuation and scatter corrections were applied to the emission data. Data were reconstructed using the reprojection algorithm with an axial and transaxial Hanning filter that had a 0.5 cutoff frequency. The resulting images had a spatial resolution of approximately 5$7 \mathrm{~mm}$ in full width at half maximum.

\section{Displacement experiments}

PET experiments performed during ethanol exposure (acute group) were prolonged by displacement procedure to address the specificity of ${ }^{18} \mathrm{~F}-\mathrm{DPA}-714$ binding to the brain in this situation: after 55 min acquisition, animals were injected $i . v$ with PK-11195 (1.5 mg/kg) and PET acquisition was continued for $60 \mathrm{~min}$. An additional animal of the set-up group underwent a 115 min ${ }^{18}$ F-DPA-714 PET scan without displacement during initial ethanol exposure to serve as reference animal.

\section{Metabolite-corrected arterial input function}

During the PET scan, blood samples $(200 \mu \mathrm{L})$ were collected at selected times from the femoral artery to establish total radioactivity kinetics in arterial plasma. Samples were centrifuged $\left(3 \mathrm{~min}, 2054 \mathrm{~g}, 4^{\circ} \mathrm{C}\right)$ and radioactivity in cell-free plasma $(100 \mu \mathrm{L})$ was counted. Additional samples $(500 \mu \mathrm{L})$ were withdrawn to determine the fraction of parent ${ }^{18} \mathrm{~F}$-DPA-714 in plasma using a validated solid phase extraction method (Peyronneau et al. 2013). The fraction of parent ${ }^{18} \mathrm{~F}$-DPA-714 versus time was fitted using a 2-exponential decay equation and applied to the total radioactivity kinetics to estimate the metabolite-corrected arterial input function of ${ }^{18} \mathrm{~F}-\mathrm{DPA}-714$. For each animal, unmetabolized parent ${ }^{18} \mathrm{~F}-\mathrm{DPA}-714$ in plasma was expressed as standardized uptake value $($ SUV $=$ (radioactivity per $\mathrm{mL}$ plasma/injected radioactivity) $\mathrm{x}$ body weight) versus time.

\section{PET data analysis}


The regions of interests (ROIs) were drawn on MR images. ROls were then applied to coregistered dynamic PET images. Regional time activity curves (TACs) were generated by calculating the mean radioactivity in selected brain regions, including the caudate nucleus, cerebellum, frontal cortex, hippocampus, occipital cortex, putamen, temporal cortex, thalamus, white matter and whole-brain. PET kinetics in each region were corrected for fluorine-18 decay, injected radioactivity and animal weight and expressed in SUV versus time. In order to compare the brain kinetics of ${ }^{18} \mathrm{~F}-\mathrm{DPA}-714$ obtained in the 3 different conditions, the distribution volume $\left(\mathrm{V}_{\mathrm{T}} ; \mathrm{mL} . \mathrm{cm}^{-3}\right)$ was then estimated for each region using the Logan graphical method, considering the brain TACs from 0 to $50 \mathrm{~min}$ (prior to the displacement performed in the acute group) and the corresponding metabolite-corrected arterial input function (PMOD ${ }^{\circledR}$ software version 3.6, Zurich, Switzerland).

During acute alcohol exposure, ${ }^{18} \mathrm{~F}-\mathrm{DPA}-714$ specific (reversible) binding was confirmed using displacement experiments. The extent of displacement was calculated as the percentage decrease in regional SUV measured before $(50 \mathrm{~min})$ and after $(75 \mathrm{~min})$ displacement using PK-11195. Data were compared to those obtained in a reference experiment (115 min scan without displacement) obtained using an animal of the set-up group.

Impact of alcohol exposure on ${ }^{18} \mathrm{~F}-\mathrm{DPA}-714$ binding to plasma proteins

The infusion protocol was administered to 3 other adult baboons to address the impact of ethanol exposure on ${ }^{18} \mathrm{~F}-\mathrm{DPA}-714$ binding to plasma proteins in parallel conditions. Arterial plasma samples were withdrawn before and after $30 \mathrm{~min}$ infusion of ethanol. The ${ }^{18} \mathrm{~F}$-DPA714 fraction that is not bound to baboon plasma proteins was measured as previously described (Tournier et al. 2012). Standard amounts of ${ }^{18} \mathrm{~F}$-DPA-714 solution ( $\left.50 \mathrm{kBq}\right)$ were added to $200 \mu \mathrm{L}$ plasma samples. These solutions were applied to Microcon ${ }^{\circledR}$ filtration devices containing an YM-10 membrane (Millipore, France). Ultrafiltration was performed by centrifugation for $20 \mathrm{~min}$ at $10,000 \mathrm{~g}$. The resulting ultrafiltrate $\left(\sim 100 \mu \mathrm{L}, \mathrm{C}_{\mathrm{FP}}\right)$ and a sample 
of plasma $\left(\mathrm{C}_{\mathrm{P}}\right)$ were counted to determine their ${ }^{18} \mathrm{~F}$ activities. The free fraction $\left(\mathrm{f}_{\mathrm{P}}\right)$ of ${ }^{18} \mathrm{~F}$ DPA-714 was calculated as: $\mathrm{f}_{\mathrm{P}}=\mathrm{C}_{\mathrm{FP}} / \mathrm{C}_{\mathrm{P}}$.

Statistical analysis

Results are given as mean \pm standard deviation (SD). PET data were compared using a 2way unpaired ANOVA with "condition" (baseline, acute, long-term) and "brain region" as factors, followed by Tukey's post-hoc test ( $R$ software, version 3.1; https://www.rproject.org/). Level of statistical significance was set to $p<0.05$. 


\section{RESULTS}

Figure 1 shows the plasma kinetics of ethanol measured during PET experiments. Immediately before ${ }^{18}$ F-DPA-714 injection, after 30 min infusion, ethanol concentration in plasma ranged from 0.7 to $1 \mathrm{~g} \cdot \mathrm{L}^{-1}$. Ethanol exposure remained constant and was $\sim 0.8 \mathrm{~g} \cdot \mathrm{L}^{-1}$ at the end of PET experiments. The infusion was well tolerated and we did not notice any increase in the time for the baboons to wake up and to eat their meal.

Figure 2 displays the PET images obtained in the same baboon before, during and 7 months after alcohol exposure. In alcohol-naive animals (baseline), ${ }^{18}$ F-DPA-714 brain radioactivity peaked rapidly $\left(T_{\max } \sim 2 \mathrm{~min}\right)$, followed by a fast decrease of the brain radioactivity $\left(\mathrm{SUV}_{50}\right.$ min $=0.5 \pm 0.1)$ (Fig. 3). Ethanol infusion (acute) resulted in a delayed $T_{\max }(\sim 6 \mathrm{~min})$ and $\mathrm{a}$ slower clearance of the tracer from the brain. This resulted in a higher uptake of ${ }^{18} \mathrm{~F}$-DPA-714 in all tested brain regions $\left(\mathrm{SUV}_{50 \mathrm{~min}}=1.1 \pm 0.1\right)$.

Displacement with PK-11195 resulted in a fast washout of the brain radioactivity, showing the reversible and specific binding of ${ }^{18} \mathrm{~F}$-DPA-714 to TSPO (Fig. 4). This result suggests that the increase in ${ }^{18} \mathrm{~F}$-DPA-714 uptake during ethanol infusion reflects a higher specific binding rather than the impact of alcohol on cerebral blood flow (Strang et al. 2015). The extent of displacement was similar across brain regions and ranged from $21 \%$ to $33 \%$ (Table 1). For comparison, washout of the radioactivity after displacement was 1.6 to 4.2 -fold higher than in the reference animal (alcohol exposure without displacement) (Fig. 4, Table 1).

Interestingly, ${ }^{18}$ F-DPA-714 brain kinetics measured several months after initial alcohol exposure, in the absence of ethanol infusion, remained higher than baseline, with $T_{\max } \sim 6$ $\min$ and $\mathrm{SUV}_{50 \mathrm{~min}}=1.0 \pm 0.3$ (Fig. 3).

The plasma metabolism of ${ }^{18} \mathrm{~F}$-DPA-714 as well as the plasma kinetics of parent ${ }^{18} \mathrm{~F}$-DPA714 did not differ between the tested groups (Fig. 3). Kinetic modelling, using the metabolitecorrected input function of ${ }^{18}$ F-DPA-714 in each experiment, demonstrated a significant increase $(p<0.001)$ in $V_{T}$ during alcohol infusion when compared to the baseline condition. 
The regional increase ranged from 58 to $138 \%$ but differences between brain regions could not be analyzed because of the small number of animals (Fig. 5). As a comparison, second anesthesia performed in the "control" animal in the absence of alcohol exposure did not increase ${ }^{18}$ F-DPA-714 binding to the brain (Fig. 5).

Dedicated experiments performed in 3 other animals showed negligible difference between ${ }^{18}$ F-DPA-714 binding to plasma proteins before $\left(f_{P}=13.1 \%, 15.6 \%\right.$ and $\left.16.7 \%\right)$ and during ethanol infusion ( $f_{P}=13.6 \%, 15.9 \%$ and $17.0 \%$, respectively).

In the long-term condition, ${ }^{18} \mathrm{~F}-\mathrm{DPA}-714$ brain $\mathrm{V}_{\mathrm{T}}$ remained higher $(\mathrm{p}<0.001)$ than baseline but were significantly lower $(p<0.001)$ than those measured during alcohol exposure (Fig. 5 ). The coefficient of variation of brain $\mathrm{V}_{\mathrm{Ts}}(\mathrm{CV}=100 \times \mathrm{SD} / \mathrm{mean})$ were lower in the baseline $(\mathrm{CV}$ $=19 \%)$ and the acute conditions $(\mathrm{CV}=5 \%)$ compared to the long-term conditions $(\mathrm{CV}=$ $25 \%$ ), suggesting higher variability in the long-term effects of alcohol. In animal 3 , scanned 7 months after alcohol exposure, long-term $\mathrm{V}_{\mathrm{T}}$ remained at the same level than acute $\mathrm{V}_{\mathrm{T}}$ (Fig. 5). Long-term $\mathrm{V}_{\mathrm{T}}$ tent to decrease in animal 1 and 2, scanned 12 and 7 months after alcohol exposure, respectively (Fig. 5). As a comparison, no increase in ${ }^{18} \mathrm{~F}-\mathrm{DPA}-714$ brain $\mathrm{V}_{\mathrm{T}}$ could be observed in the "control" alcohol-naïve animal, up to 14 months after the first ${ }^{18} \mathrm{~F}$-DPA-714 PET experiment (Fig. 5). 


\section{DISCUSSION}

Emerging evidence from animal studies supports a role of the neuroimmune system in many actions of alcohol to the CNS (Mayfield et al. 2013). Alcohol-induced neuroinflammation is clearly related to brain damages after excessive binge drinking (Alfonso-Loeches et al. 2010). The influence of the first alcohol exposure in young individuals remained to be investigated. For obvious ethical reasons, it is not possible to investigate the effect of an initial alcohol intake in Human. The neuroimmune response to an initial alcohol exposure, which mimics the binge drinking situation, was thus investigated using TSPO PET imaging in the brain of adolescent baboons.

The first important finding of this study is the immediate increase in ${ }^{18} \mathrm{~F}-\mathrm{DPA}-714$ binding to the brain observed in vivo during ethanol exposure. The effect was shown reversible by displacement using PK-11195, suggesting specific binding to TSPO. We showed that ethanol exposure was not likely to increase ${ }^{18} \mathrm{~F}$-DPA-714 fraction that is not bound to plasma proteins. Therefore, enhanced $f_{P}$ is not an explanation for the increase in ${ }^{18} \mathrm{~F}-\mathrm{DPA}-714 \mathrm{~V}_{\mathrm{T}}$ observed in this condition.

This effect corroborates with the direct action of ethanol and its metabolites on innate brain immunity, which is hypothesized to account for the acute effects of alcohol consumption (Alfonso-Loeches et al. 2010). The increase in ${ }^{18} \mathrm{~F}-\mathrm{DPA}-714$, as well as the substantial displacement using PK-11195, was observed globally across tested brain regions, suggesting that the neuroimmune response to acute alcohol exposure is not restricted to any specific neuronal circuitry or function or to any neurotransmitter system.

Previous autoradiographic studies have used TSPO as an ex vivo biomarker of glial activation in the context of alcohol exposure. An increase in the binding of the TSPO radioligand ${ }^{11} \mathrm{C}$-DAA1106 has been reported after intra-striatal injection of ethanol in rats (Maeda et al. 2007). An early increase in the binding of the reference TSPO ligand ${ }^{3} \mathrm{H}-\mathrm{PK}$ 11195 has been reported after 4 days of ethanol intake in the brain of rats (Obernier et al. 2013). In vivo PET imaging studies have reported a slight but significant increase in the brain 
kinetics of ${ }^{11} \mathrm{C}-\mathrm{PK}-11195$ in the striatum, 4 days after intra-striatal injection of ethanol (Toyama et al. 2008). The dramatic effect observed in our study may be due to species differences in the neuroimmune response to ethanol exposure or to a lower sensitivity of the first generation ${ }^{11} \mathrm{C}-\mathrm{PK}-11195$ TSPO PET radioligand to pro-inflammatory stimuli compared to ${ }^{18}$ F-DPA-714 (Boutin et al. 2013).

The second important finding of this study was that ${ }^{18} \mathrm{~F}-\mathrm{DPA}-714$ brain distribution measured several months after an initial and unique exposure to alcohol, remained significantly higher than at baseline, i.e measured in the alcohol-naive subjects. This long-lasting effect suggests that the neuroimmune footprints of acute alcohol exposure are poorly reversible and durably account for the ${ }^{18} \mathrm{~F}$-DPA-714 PET signal. In rats, previous autoradiographic studies have shown a prolonged TSPO overexpression in several brain regions after a 4-day binge exposure, using measurements performed several months after alcohol exposure (Marshall et al. 2013). Our study suggests that a single and initial exposure to alcohol-induced "priming" of glial cell activity can be detected using TSPO PET imaging. Further experiments are thus required to investigate the reversibility of this effect and its impact for further glial function and brain immunity.

TSPO PET signal in the brain was shown to reveal reactive microglia but may also involve reactive astrocytes (Lavisse et al. 2012). Previous studies involving more specific biomarkers of neuroimmunity are thus useful to refer in order to provide a molecular correlate to the alcohol-induced increase in ${ }^{18} \mathrm{~F}$-DPA-714 binding to the brain. Studies using Toll-like receptor 4 (TLR4) deficient mice have elucidated the pivotal role of these receptors in the ethanolinduced immune response (Alfonso-Loeches et al. 2010). Immunohistochemistry studies, performed in adolescent rats, reported a long-lasting microglial activation after 4-days binge drinking (ethanol blood concentration $=3$ to $4 \mathrm{~g} / \mathrm{L}$ ) with increased expression of Iba1 and CD11b (McClain et al. 2011; Marshall et al. 2013). Interestingly, binge drinking did not impact the expression of CD-68, indicating that microglia did not reach the phagocytic stage. Accordingly, the expression of the anti-inflammatory cytokines IL-10 and TGF- $\beta$ was 
increased whereas no increase in the pro-inflammatory cytokines IL- 6 and TNF- $\alpha$ could be detected (Marshall et al. 2013). Further experiments are thus required to assess whether increased TSPO PET signal observed during and after acute ethanol exposure in our study reflects a partial microglia activation or a typical neuroinflammatory state (McClain et al. 2011). Alternative PET radioligands, which may be specific to each glial activation state, would be useful to address the cellular and molecular features of both the acute and longterm neuroimmune response to alcohol exposure in nonhuman primates and humans.

The present study aimed at highlighting the neuroimmune response to an initial and unique alcohol exposure in adolescent baboons. This situation reflects early alcohol intake in young individuals rather than the neuroimmune component of alcohol dependence or withdrawal. Interestingly, recent PET studies have unveiled a significant decrease in the binding of ${ }^{11} \mathrm{C}$ PBR28, another TSPO radioligand, in different brain regions of alcohol-dependent patients compared to matched controls, with medically acceptable alcohol consumption (Kalk et al. 2017; Hillmer et al. 2017). These ${ }^{11}$ C-PBR28 PET experiments have been in patients apart from alcohol exposure. In a first study, hippocampal ${ }^{11} \mathrm{C}-\mathrm{PBR} 28 \mathrm{~V}_{\mathrm{T}}$ was positively correlated with verbal memory performance (Kalk et al. 2017). In the other study, a negative association between ${ }^{11} \mathrm{C}$-PBR28 $\mathrm{V}_{\mathrm{T}}$ in the hippocampus and striatum with alcohol dependence severity was reported (Hillmer et al. 2017). One may thus hypothesize that differential regulation of glial function, several years after the initial "priming" of glial cell function by early alcohol exposure, may play a role in the development of alcohol dependence and/or alcohol-induced brain disorders (Hillmer et al. 2017).

Variability in the baseline PET kinetics of ${ }^{18}$ F-DPA-714 has been reported when studying baboons scanned in a same (Auvity et al. 2016) or different PET centers (James et al. 2008; Saba et al. 2015). Interestingly, high baseline ${ }^{18} \mathrm{~F}-\mathrm{DPA}-714$ brain distribution has been hypothesized to account for higher susceptibility to further pro-inflammatory stimulus (Auvity et al. 2016). Accordingly, previous alcohol exposure was shown to potentiate the endotoxininduced cytokine release and neuroinflammation in mice (Qin et al. 2008). Conversely, ex 
vivo response of peripheral monocytes to lipopolysaccharide stimulation was shown lower in alcohol-dependent patients compared to control subjects (Hillmer et al. 2017). Further research is thus needed to elucidate the interplay between the neuroimmune response to early and acute alcohol exposure and the implication of neuroimmunity for the development of brain damages, alcohol and/or drug abuse, and the development of alcohol dependence (Hutchinson \& Watkins 2013; Mayfield et al. 2013).

\section{CONCLUSION}

The neuroimmune response to alcohol exposure was non-invasively highlighted using TSPO PET imaging in adolescent baboons. We found an immediate and prolonged increase in the brain distribution of ${ }^{18} \mathrm{~F}$-DPA-714 after a unique and single alcohol exposure. Our study shows that TSPO PET imaging can be useful to investigate the neuroimmune component of the acute effects of alcohol to the CNS and to assess its implication for brain immunity, toxicity and alcohol-use disorders.

\section{ACKNOWLEGEMENTS}

This work was performed on a platform of France Life Imaging network partly funded by the grant ANR-11-INBS-0006. We thank Jérôme Cayla and Yoan Fontyn for helpful technical assistance.

\section{AUTHORS CONTRIBUTION}

WS and NT were responsible for the study concept and design. WS and SG contributed to the acquisition of animal data. BK was in charge with the development and production of ${ }^{18} \mathrm{~F}$ DPA-714. CC, SA and NT developed and performed analytical chemistry experiments. WS, SA, VK and CL performed imaging data analysis and interpretation. IB provided critical 
revision of the manuscript for important intellectual content. The authors declare that they have no conflict of interest. All authors critically reviewed content and approved final version submitted for publication.

\section{REFERENCES}

Alfonso-Loeches S, Pascual-Lucas M, Blanco AM, Sanchez-Vera I \& Guerri C (2010) Pivotal role of TLR4 receptors in alcohol-induced neuroinflammation and brain damage. J Neurosci $30: 8285-8295$.

Auvity S, Saba W, Goutal S, Leroy C, Buvat I, Cayla J, Caillé F, Bottlaender M, Cisternino S \& Tournier N (2016) Acute morphine exposure increases the brain distribution of [18F]DPA714, a PET biomarker of glial activation in nonhuman primates. Int $J$ Neuropsychopharmacol doi: 10.1093/ijnp/pyw077. [Epub ahead of print]

Bell RL, Lopez MF, Cui C, Egli M, Johnson KW, Franklin KM \& Becker HC (2015) Ibudilast reduces alcohol drinking in multiple animal models of alcohol dependence. Addict Biol 20:38-42.

Blednov YA, Ponomarev I, Geil C, Bergeson S, Koob GF \& Harris RA (2012) Neuroimmune regulation of alcohol consumption: behavioral validation of genes obtained from genomic studies. Addict Biol 17:108-120.

Boutin H, Prenant C, Maroy R, Galea J, Greenhalgh AD, Smigova A, Cawthorne C, Julyan P, Wilkinson SM, Banister SD, Brown G, Herholz K, Kassiou M \& Rothwell NJ (2013) [18F]DPA714: direct comparison with [11C]PK11195 in a model of cerebral ischemia in rats. PloS One 8:e56441.

Bühler M \& Mann K (2011) Alcohol and the human brain: a systematic review of different neuroimaging methods. Alcohol Clin Exp Res 35:1771-1793.

Crews FT, Vetreno RP, Broadwater MA \& Robinson DL (2016) Adolescent Alcohol Exposure Persistently Impacts Adult Neurobiology and Behavior. Pharmacol Rev 68:1074-1109.

Ekins BR, Rollins DE, Duffy DP \& Gregory MC (1985) Standardized Treatment of Severe Methanol Poisoning With Ethanol and Hemodialysis. West J Med 142:337-340.

Fillmore MT \& Jude R (2011) Defining 'binge' drinking as five drinks per occasion or drinking to a .08\% BAC: which is more sensitive to risk? Am J Addict 20:468-475.

Guizzetti M, Zhang X, Goeke C \& Gavin DP (2014) Glia and neurodevelopment: focus on fetal alcohol spectrum disorders. Child Neurodev Psychiatry 2:123.

Hamelin L, Lagarde J, Dorothée G, Leroy C, Labit M, Comley RA, de Souza LC, Corne H, Dauphinot L, Bertoux M, Dubois B, Gervais P, Colliot O, Potier MC, Bottlaender M, Sarazin M \& Clinical IMABio3 team (2016) Early and protective microglial activation in Alzheimer's disease: a prospective study using 18F-DPA-714 PET imaging. Brain J Neurol 139:12521264. 
Haorah J, Ramirez SH, Floreani N, Gorantla S, Morsey B \& Persidsky Y (2008) Mechanism of alcohol-induced oxidative stress and neuronal injury. Free Radic Biol Med 45:1542-1550.

Hutchinson MR \& Watkins LR (2013) Why is Neuroimmunopharmacology crucial for the future of addiction research? Neuropharmacology. 76 Pt B:218-227.

Jacobs AH, Tavitian B \& INMiND consortium (2012) Noninvasive molecular imaging of neuroinflammation. J Cereb Blood Flow Metab 32:1393-1415.

James ML, Fulton RR, Vercoullie J, Henderson DJ, Garreau L, Chalon S, Dolle F, Costa B, Selleri S, Guilloteau D \& Kassiou M (2008) DPA-714, a new translocator protein-specific ligand: synthesis, radiofluorination, and pharmacologic characterization. J Nucl Med 49:814822.

Kalk NJ, Guo Q, Owen D, Cherian R, Erritzoe D, Gilmour A, Ribeiro AS, McGonigle J, Waldman A, Matthews P, Cavanagh J, Mclnnes I, Dar K, Gunn R, Rabiner EA \& LingfordHughes AR (2017) Decreased hippocampal translocator protein (18 kDa) expression in alcohol dependence: a [(11)C]PBR28 PET study. Transl Psychiatry 7:e996.

Kristoffersen L, Stormyhr L-E \& Smith-Kielland A (2006) Headspace gas chromatographic determination of ethanol: the use of factorial design to study effects of blood storage and headspace conditions on ethanol stability and acetaldehyde formation in whole blood and plasma. Forensic Sci Int 161:151-157.

Kuhnast B, Damont A, Hinnen F, Catarina T, Demphel S, Le Helleix S, Coulon C, Goutal S, Gervais P \& Dollé $F$ (2012) [18F]DPA-714, [18F]PBR111 and [18F]FEDAA1106-selective radioligands for imaging TSPO $18 \mathrm{kDa}$ with $\mathrm{PET}$ : automated radiosynthesis on a TRACERLAb FX-FN synthesizer and quality controls. Appl Radiat Isot 70:489-497.

Lavisse S, García-Lorenzo D, Peyronneau M-A, Bodini B, Thiriez C, Kuhnast B, Comtat C, Remy P, Stankoff B \& Bottlaender M (2015) Optimized Quantification of Translocator Protein Radioligand ${ }^{18}$ F-DPA-714 Uptake in the Brain of Genotyped Healthy Volunteers. $J$ Nucl Med 56:1048-1054.

Lavisse S, Guillermier M, Hérard A-S, Petit F, Delahaye M, Van Camp N, Ben Haim L, Lebon V, Remy P, Dollé F, Delzescaux T, Bonvento G, Hantraye P \& Escartin C (2012) Reactive astrocytes overexpress TSPO and are detected by TSPO positron emission tomography imaging. J Neurosci 32:10809-10818.

Lavisse S, Inoue K, Jan C, Peyronneau MA, Petit F, Goutal S, Dauguet J, Guillermier M, Dollé F, Rbah-Vidal L, Camp NV, Aron-Badin R, Remy P \& Hantraye P (2014) [18F]DPA-714 PET imaging of translocator protein TSPO $(18 \mathrm{kDa})$ in the normal and excitotoxicallylesioned nonhuman primate brain. Eur J Nucl Med Mol Imaging 42:478-494.

Lovinger DM \& Crabbe JC (2005) Laboratory models of alcoholism: treatment target identification and insight into mechanisms. Nat Neurosci 8:1471-1480.

Maeda J, Higuchi M, Inaji M, Ji B, Haneda E, Okauchi T, Zhang M-R, Suzuki K \& Suhara T (2007) Phase-dependent roles of reactive microglia and astrocytes in nervous system injury as delineated by imaging of peripheral benzodiazepine receptor. Brain Res 1157:100-111.

Marshall SA, McClain JA, Kelso ML, Hopkins DM, Pauly JR \& Nixon K (2013) Microglial 
activation is not equivalent to neuroinflammation in alcohol-induced neurodegeneration: The importance of microglia phenotype. Neurobiol Dis 54:239-251.

Mayfield J, Ferguson L \& Harris RA (2013) Neuroimmune signaling: a key component of alcohol abuse. Curr Opin Neurobiol 23:513-520.

McClain JA, Morris SA, Deeny MA, Marshall SA, Hayes DM, Kiser ZM \& Nixon K (2011) Adolescent binge alcohol exposure induces long-lasting partial activation of microglia. Brain Behav Immun 25 Suppl 1:S120-128.

Montesinos J, Alfonso-Loeches S \& Guerri C (2016) Impact of the Innate Immune Response in the Actions of Ethanol on the Central Nervous System. Alcohol Clin Exp Res 40:2260 2270.

Morris LS, Dowell NG, Cercignani M, Harrison NA \& Voon V (2017) Binge drinking differentially affects cortical and subcortical microstructure. Addict Biol doi: 10.1111/adb.12493. [Epub ahead of print].

Obernier JA, White AM, Swartzwelder HS \& Crews FT (2002) Cognitive deficits and CNS damage after a 4-day binge ethanol exposure in rats. Pharmacol Biochem Behav 72:521532.

Pascual M, Montesinos J, Marcos M, Torres J-L, Costa-Alba P, García-García F, Laso F-J \& Guerri C (2016) Gender differences in the inflammatory cytokine and chemokine profiles induced by binge ethanol drinking in adolescence. Addict Bioldoi: 10.1111/adb.12461. [Epub ahead of print].

Pedersen W \& von Soest T (2015) Adolescent Alcohol Use and Binge Drinking: An 18-Year Trend Study of Prevalence and Correlates. Alcohol Alcohol 50:219-225.

Peyronneau M-A, Saba W, Goutal S, Damont A, Dollé F, Kassiou M, Bottlaender M \& Valette $\mathrm{H}$ (2013) Metabolism and quantification of [(18)F]DPA-714, a new TSPO positron emission tomography radioligand. Drug Metab Dispos 41:122-131.

Qin L, He J, Hanes RN, Pluzarev O, Hong J-S \& Crews FT (2008) Increased systemic and brain cytokine production and neuroinflammation by endotoxin following ethanol treatment. $J$ Neuroinflammation 5:10.

Saba W, Goutal S, Kuhnast B, Dollé F, Auvity S, Fontyn Y, Cayla J, Peyronneau M-A, Valette H \& Tournier N (2015) Differential influence of propofol and isoflurane anesthesia in a non-human primate on the brain kinetics and binding of [(18)F]DPA-714, a positron emission tomography imaging marker of glial activation. Eur J Neurosci 42:1738-1745.

Saito M, Chakraborty G, Hui M, Masiello K \& Saito M (2016) Ethanol-Induced Neurodegeneration and Glial Activation in the Developing Brain. Brain Sci 6.

Strang NM, Claus ED, Ramchandani VA, Graff-Guerrero A, Boileau I \& Hendershot CS (2015) Dose-dependent effects of intravenous alcohol administration on cerebral blood flow in young adults. Psychopharmacology (Berl) 232:733-744. 
Tournier N, Cisternino S, Peyronneau M-A, Goutal S, Dolle F, Scherrmann J-M, Bottlaender M, Saba W \& Valette H (2012) Discrepancies in the P-glycoprotein-mediated transport of (18)F-MPPF: a pharmacokinetic study in mice and non-human primates. Pharm Res 29:2468-2476.

Toyama H, Hatano K, Suzuki H, Ichise M, Momosaki S, Kudo G, Ito F, Kato T, Yamaguchi H, Katada K, Sawada M \& Ito K (2008) In vivo imaging of microglial activation using a peripheral benzodiazepine receptor ligand: [11C]PK-11195 and animal PET following ethanol injury in rat striatum. Ann Nucl Med 22:417-424.

Trudell JR, Messing RO, Mayfield J \& Harris RA (2014) Alcohol dependence: molecular and behavioral evidence. Trends Pharmacol Sci 35:317-323.

Vetreno RP \& Crews FT (2014) Current hypotheses on the mechanisms of alcoholism. Handb Clin Neurol 125:477-497.

Vivash L \& O'Brien TJ (2016) Imaging Microglial Activation with TSPO PET: Lighting Up Neurologic Diseases? J Nucl Med 57:165-168.

Wu Y, Lousberg EL, Moldenhauer LM, Hayball JD, Robertson SA, Coller JK, Watkins LR, Somogyi AA \& Hutchinson MR (2011) Attenuation of microglial and IL-1 signaling protects mice from acute alcohol-induced sedation and/or motor impairment. Brain Behav Immun 25 Suppl 1:S155-164. 


\section{FIGURE LEGENDS}

Fig.1 Blood-ethanol concentrations measured during the ethanol infusion protocol. Alcoholnaïve baboons that participated to the PET study were injected with a bolus ethanol dose $(0.6 \mathrm{~g} / \mathrm{kg}$ in $10 \mathrm{~min})$ followed by ethanol infusion $(0.1 \mathrm{~g} / \mathrm{kg} / \mathrm{h})$. Individual blood ethanol kinetics in plasma $\left(\mathrm{g} \cdot \mathrm{L}^{-1}\right)$ are reported for Animal 1, 2 and 3.

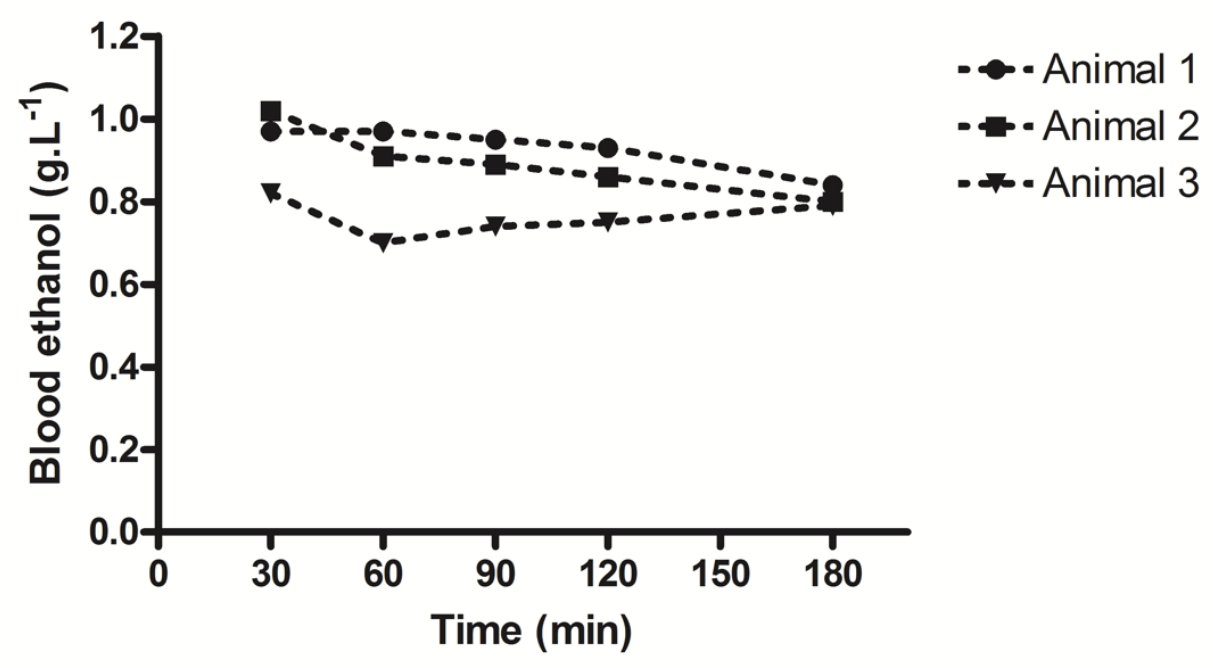

Fig. $2{ }^{18}$ F-DPA-714 brain PET images obtained before $(A)$, during $(B)$ and 7 months after $(C)$ an initial ethanol exposure $\left(\sim 0.8 \mathrm{~g} \cdot \mathrm{L}^{-1}\right)$ in a baboon (Animal 1$)$. These are summed (10 to 50 $\min$ ) and SUV-normalized PET images obtained after injection of ${ }^{18} \mathrm{~F}-\mathrm{DPA}-714$.

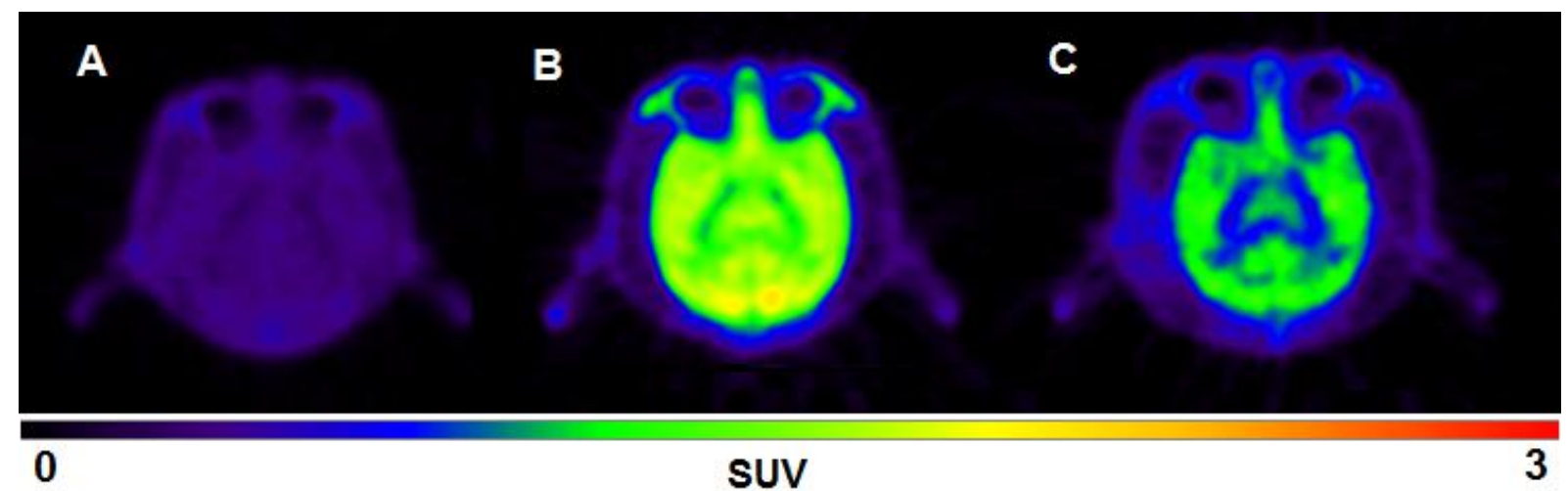


Fig. $3{ }^{18} \mathrm{~F}$-DPA-714 kinetics in the brain (A) and in plasma (B) obtained before, during and several months after an initial exposure to alcohol. Data are shown as time activity curves (SUV versus time) expressed as mean \pm 1 S.D. The fraction (\%) of parent ${ }^{18} \mathrm{~F}$-DPA-714 versus time in each condition is shown in C.

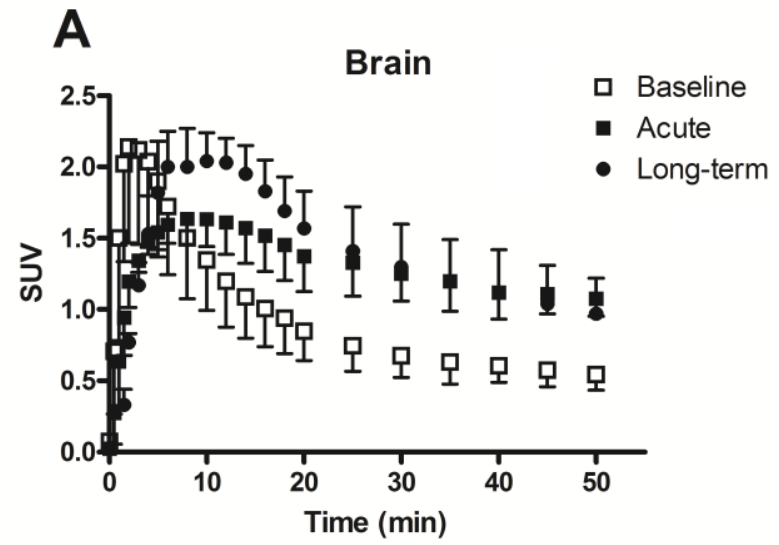

\section{B}
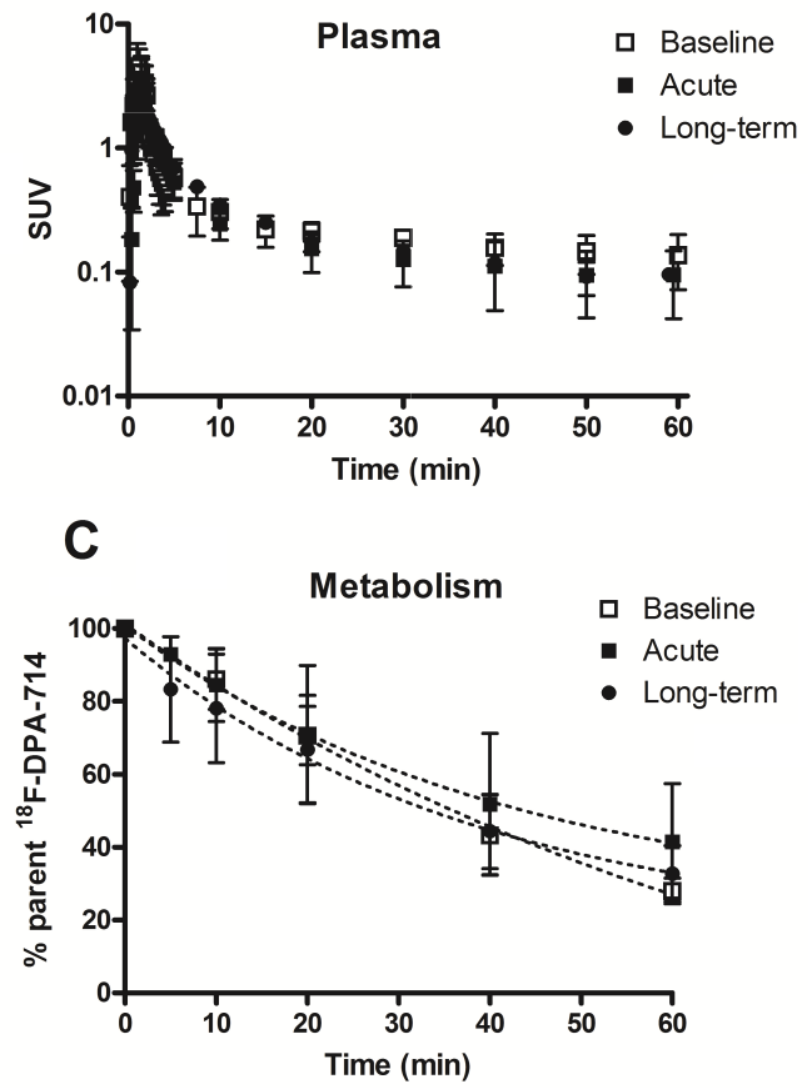
Fig. 4 Influence of displacement using unlabeled PK11195 on the brain kinetics of ${ }^{18} \mathrm{~F}$-DPA714 in several brain regions. Representative time-activity curves (TACs, SUV versus min) obtained in selected brain regions of a baboon (Animal 1). During the ethanol infusion protocol (solid lines), animal was injected i.v with ${ }^{18}$ F-DPA-714. After 55 min PET acquisition, animal received an i.v bolus of unlabeled PK-11195 $(1.5 \mathrm{mg} / \mathrm{kg})$ followed by $60 \mathrm{~min}$ acquisition. Corresponding TACs obtained in a reference animal without displacement and during alcohol exposure are shown as dashed lines.

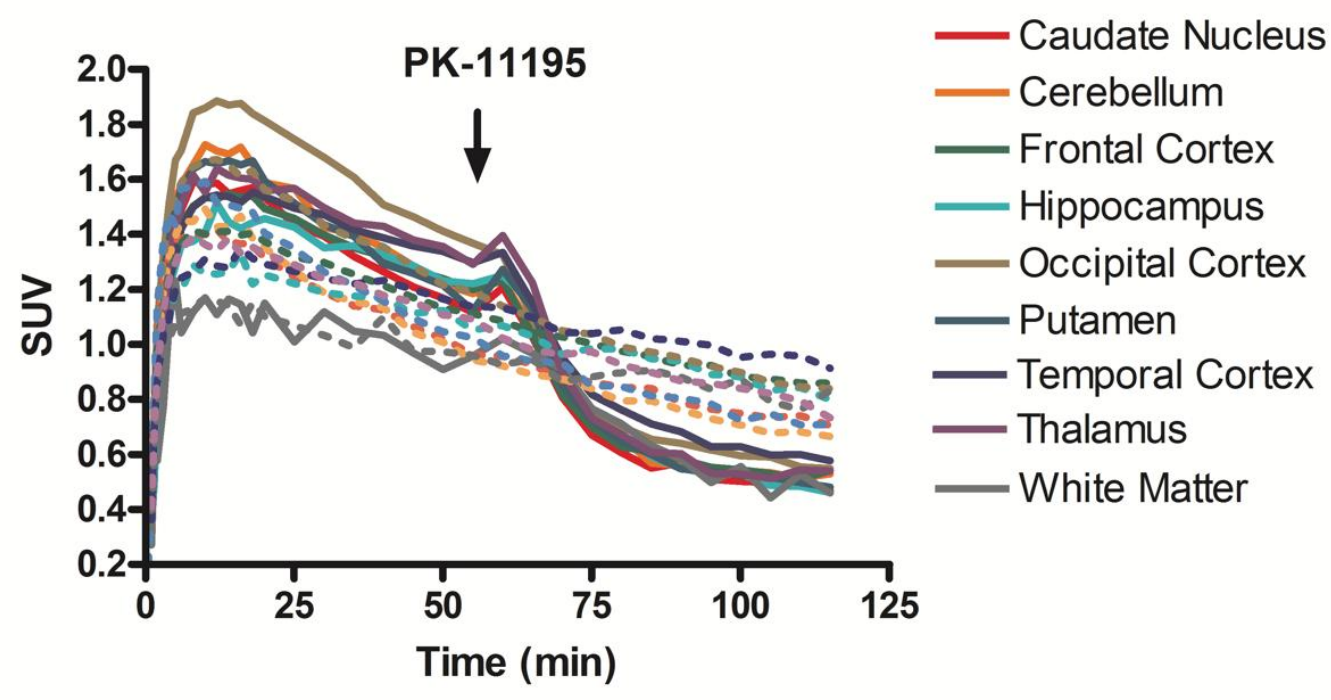


Fig. 5 The volume of distribution $\left(\mathrm{V}_{\mathrm{T}} ; \mathrm{mL}^{\mathrm{cm}} \mathrm{cm}^{-3}\right)$ of ${ }^{18} \mathrm{~F}-\mathrm{DPA}-714$ was estimated using the Logan plot analysis in selected brain regions before, during and several months after an initial exposure to alcohol (A). Ctx $=$ cortex. Data are shown as mean \pm 1 S.D ( $n=3$ animals). Statistical significance is shown as ${ }^{* *} \mathrm{p}<0.001$. Individual $\mathrm{V}_{\mathrm{T}} \mathrm{s}$ estimated for the whole brain in the different tested conditions are shown in B. Data obtained in a "control" alcohol-naïve animal, that did not receive alcohol during the study, are also displayed.
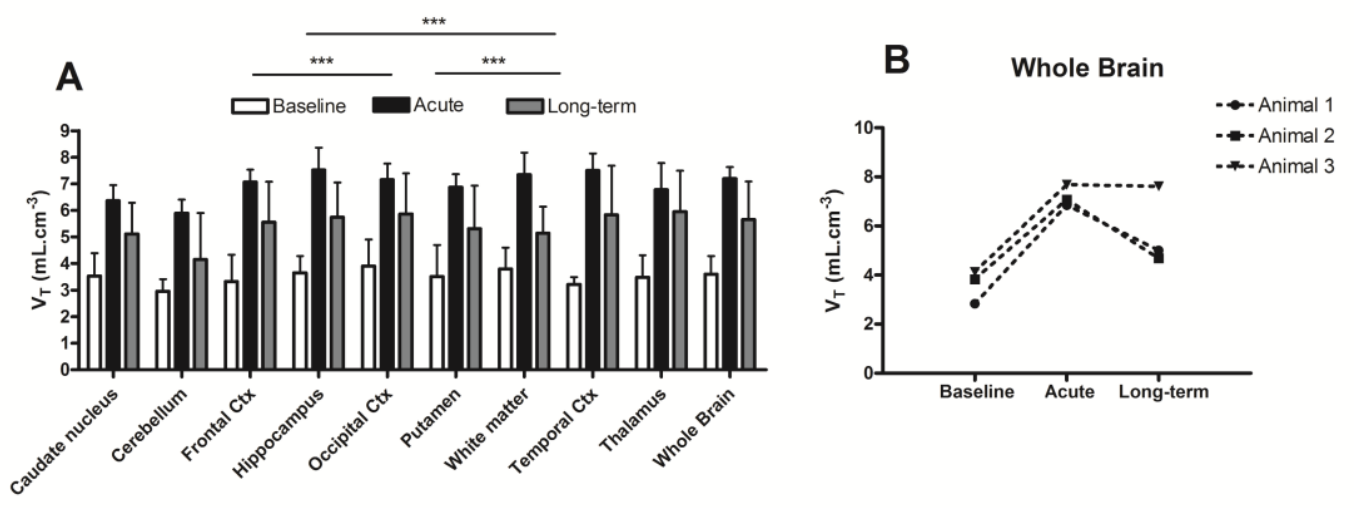
Table 1 Displacement of ${ }^{18}$ F-DPA-714 brain radioactivity obtained using unlabeled PK11195 in baboons during alcohol exposure. Individual values (\%) are reported for each animal and are expressed as a percentage change between $\mathrm{SUV}_{50 \text { min }}$ (before displacement) and $\mathrm{SUV}_{75}$ min (after displacement) in several brain regions. Regional data were compared to those obtained in a reference animal (during alcohol exposure, without displacement). Data are shown as mean $\% \pm 1$ SD $(n=3)$.

\begin{tabular}{|c|c|c|c|c|c|c|c|c|c|}
\hline & $\begin{array}{l}\text { Caudate } \\
\text { Nucleus }\end{array}$ & Cerebellum & $\begin{array}{l}\text { Frontal } \\
\text { Cortex }\end{array}$ & Hippocampus & $\begin{array}{c}\text { Occipital } \\
\text { Cortex }\end{array}$ & Putamen & $\begin{array}{c}\text { Temporal } \\
\text { Cortex }\end{array}$ & Thalamus & $\begin{array}{l}\text { White } \\
\text { Matter }\end{array}$ \\
\hline Animal 1 (\%) & 35.3 & 36.2 & 37.8 & 35.0 & 41.4 & 32.6 & 10.3 & 38.4 & 32.8 \\
\hline Animal 2 (\%) & 24.8 & 18.6 & 31.2 & 30.2 & 27.9 & 28.3 & 31.0 & 27.7 & 29.9 \\
\hline Animal $3(\%)$ & 25.6 & 25.0 & 28.5 & 33.4 & 27.8 & 25.8 & 21.0 & 33.4 & 22.9 \\
\hline Mean $\% \pm$ SD & $28.5 \pm 5.8$ & $26.6 \pm 8.9$ & $32.5 \pm 4.8$ & $32.9 \pm 2.4$ & $32.4 \pm 7.9$ & $28.9 \pm 3.4$ & $20.7 \pm 10.4$ & $33.2 \pm 5.3$ & $28.5 \pm 5.1$ \\
\hline Reference (\%) & 13.9 & 16.5 & 11.8 & 9.6 & 15.8 & 18.1 & 9.2 & 7.9 & 13.7 \\
\hline $\begin{array}{c}\text { Animal/reference } \\
\text { (Mean \% } \pm \text { SD) }\end{array}$ & $2.1 \pm 0.4$ & $1.6 \pm 0.5$ & $2.7 \pm 0.4$ & $3.4 \pm 0.2$ & $2.0 \pm 0.5$ & $1.6 \pm 0.2$ & $2.3 \pm 1.1$ & $4.2 \pm 0.7$ & $2.1 \pm 0.4$ \\
\hline
\end{tabular}

